\title{
Thinking more holistically as we grow older? Results from different tasks in two cultures
}

\author{
Xin Zhang • Helene H. Fung • \\ Jennifer Tehan Stanley • Derek M. Isaacowitz • \\ Qi Zhang
}

\begin{abstract}
The present study aims at examining culture differences in holistic thinking across younger and older adults. Ninety-four participants from Hong Kong, China and ninety participants from Boston, USA were assessed on two measures of holistic thinking: (1) a self-reported dialectical self scale; and (2) the framed line task. Although both measures showed significant culture effects, distinct age $\times$ culture patterns emerged, such that (1) in the self-reported dialectical self scale, older adults from both cultures tended to think less holistically, (2) however, for the framed line task, Chinese sample tended to show age-related changes, but the American sample did not. Findings address the controversy on whether cultures differ in age-related holistic thinking, and further suggested that measures that supposedly all measure the same concept (i.e., holistic thinking) might indeed be measuring very distinct constructs.
\end{abstract}

Keywords Age $\cdot$ Holistic thinking - Culture - Dialectical self scale · Framed line task

\footnotetext{
X. Zhang $(\bowtie) \cdot$ Q. Zhang

Department of Psychology, Peking University, Philosophy Building, Beijing, China e-mail: zhang.x@pku.edu.cn

H. H. Fung $(\bowtie)$

Department of Psychology, The Chinese University of Hong Kong, Room 328 Sino Building, Chung Chi College, Shatin New Territories, Hong Kong e-mail: hhlfung@psy.cuhk.edu.hk

J. T. Stanley

Department of Psychology, University of Akron, Akron, OH, USA

D. M. Isaacowitz

Department of Psychology, Northeastern University, Boston, MA, USA
} 
Holistic thinking is defined as an acceptance of the idea that every element in the world is interconnected (e.g., Nisbett et al. 2001). It is believed to be more common among East Asians and is usually studied in direct contrast to analytic thinking, a more westernized thinking style (e.g., Munro 1985). Indeed, findings from prior studies have revealed culture differences in holistic thinking, as reflected in attention (Chua et al. 2005; Ji et al. 2000; Masuda and Nisbett 2001), attribution (Choi and Nisbett 1998; Morris and Peng 1994), categorization (Choi et al. 1997; Norenzayan et al. 2002), memory (Masuda and Nisbett 2001), logical reasoning (Norenzayan et al. 2002), and tolerance of contradiction (Peng and Nisbett 1999). However, these prior studies were largely based on younger college students. We know little about the adult development of holistic thinking style in different cultures. The present study aimed to fill in these gaps by comparing older adults (those aged over 60 years) with younger adults (aged between 18 and 30 years) in their holistic thinking in two distinct cultures, namely Chinese and American, to see whether the culture differences in holistic thinking found in younger adults could also be observed in older adults. Another objective of the present study was to further examine the different mechanisms involved in different measures of holistic thinking.

\section{Culture and holistic thinking}

Holistic thinking can be measured in various ways, such as (1) self-report measures (Analysis-Holism Scale: Choi et al. 2007; Social Paradigm Belief Inventory: Kramer et al. 1992; Dialectical Self Scale: Spencer-Rodgers et al. 2001), and (2) behavioral measures including covariation detection ( $\mathrm{Ji}$ et al. 2000), field dependence ( $\mathrm{Ji}$ et al. 2000; Kitayama et al. 2003), change blindness (Chalfonte and Johnson 1996; Masuda and Nisbett 2006) as well as eye-movement (Chua et al. 2005), which tap the idea that a holistic thinker would pay attention to both target and contextual information, while an analytic thinker would pay more attention to target, and even neglect the contextual information. These measures all have good reliability and validity in detecting cross-cultural differences in holistic versus analytic thinking, such that younger participants from Eastern cultures are more likely to use holistic thinking to solve the tasks mentioned above than those in Western cultures. They have been used in various cross-cultural studies, for example, Kitayama et al. (2003) found in the framed line task (refer to the method section) that Japanese participants tended to pay more attention to the contextual information (an important aspect of holistic thinking) while Americans tended to ignore the contextual information. Moreover, while Westerners such as US citizens are more likely to use analytical thinking, Easterners such as the Japanese and Chinese are more likely to use holistic thinking (Peng and Nisbett 1999). However, most of these measures were used in the younger population, especially college students, and few of them have been administrated in the older population. The handful of studies that included participants over 60 years of age only used selfreport forced-choice questionnaires (e.g., Kramer et al. 1992; Kramer and Woodruff 1986) to measure thinking style in only one culture (i.e., American), which makes the generalizability of the findings very difficult to assess. 


\section{Individual differences in holistic thinking and age}

Although, numerous previous studies have confirmed the differences in holistic thinking at the culture level (e.g., Chua et al. 2005), recent investigations have suggested that the individual level differences of holistic thinking and other related culture constructs (e.g., self-concept) are not coherent. For example, in a largescale study, Na et al. (2010) measured participants' self-construal (independent vs. interdependent) and cognitive style (analytic vs. holistic). They found that all these measures could detect group/culture differences nicely as previous investigations reported; however, at the individual level, the detecting power was negligible. Their findings suggested that some cultural constructs may not have equal power in detecting individual differences, and in our opinion as well as other scholars, it is possible that the activation of self-concept and cognitive style might be situational. For example, Spencer-Rodgers et al. (2009) found that participants from dialectical cultures (e.g., Chinese and Japanese) showed greater self-concept inconsistency in the form that they exhibit less consistency in self-belief across roles and situations.

Again, the above mentioned study used only college students, making the comparison between concepts (i.e., dialectical thinking vs. holistic thinking) impossible. One way to test the individual differences in the cultural constructs might be by testing age differences (Grossmann et al. 2012). However, no previous study has investigated how holistic thinking develops across different cultures throughout the adult lifespan. Park and colleagues (Park, and Huang 2010; Park et al. 1999) have proposed a model on how culture may affect cognitive and neural functions across age. They argued that some basic "hardware of the mind" (such as source memory, working memory, and processing speed) declines in a robust manner with age, while culture may not influence much. For example, Hedden et al. (2002) reported that in the digit span backward task, a culture $\times$ age interaction was found, such that in the younger sample, Chinese participants outperformed Americans while no such difference was found in the older sample. They interpreted the finding as indicating that, when the processing requirement of the task increased with age, cultural differences in the task diminished as the culturespecific processing advantage could not continue to support the process. In contrast, other tasks might be mainly influenced by culture, and the model argues that exposure to culture results in the activation of culture-specific processing biases, facilitating members of the culture to perform this type of task. With age, this type of task is likely to show increasingly larger cultural differences, as people from different cultures acquire different culture-specific processing biases. Similar arguments have also been proposed in cross-cultural psychology. Throughout the lifespan, individuals from each culture "attune and elaborate" their self-perceptions according to their cultural frameworks (Heine et al. 1999, p. 767). Supporting this argument, You et al. (2009) found that older Americans displayed a higher level of optimism, while older Chinese displayed a lower level of optimism than their younger counterparts. They argued it was because Americans emphasize optimism more than Chinese people. 


\section{The present study}

This study aimed at examining culture differences in holistic thinking across age. We employed two different and representative measures from each category, one self-report measure, the dialectical self scale developed by Spencer-Rodgers et al. (2001), and one behavioral measure, namely the framed line task (Kitayama et al. 2003) to examine holistic thinking among Chinese and Americans younger and older adults. We expected that other than typical culture differences in these tasks, there might be different patterns of age $\times$ culture interactions, and more importantly, rather than simply testing the age $\times$ culture interaction in holistic thinking, we also aimed to distinguish between different tasks based on Park et al. (1999) model of cognitive development across culture.

For the self-report measurement, we expected the dialectical self scale to show cultural differences, and moreover, we expected a similar age-related difference in holistic thinking, for the reason that maturity and cognition rather than culture would play an important role in affecting the development of holistic thinking (Blanchard-Fields and Norris 1994). According to Diehl and Wahl's (2010) model of awareness of age-related changes, older adults' self-awareness of their cognitive declines might influence their behavior, such that the awareness of cognitive declines in older adults might make them find holistic thinking (i.e., considering both sides of an argument) more demanding and prefer a simpler way of thinking, and this preference would be universal. In other words, we would expect older adults self-report thinking holistically to a lesser extent than younger adults in both cultures.

In contrast, for the behavioral measurement, i.e., the framed-line task measuring the use of contextual information in making judgments, is likely to be influenced more by culture and socialization than age. We predicted that cultural differences would occur among our American and Chinese samples, with Americans paying less attention to contextual information on the task than Chinese. We also predicted that these age differences would be larger among Chinese participants (older adults could not ignore the contextual information) than Americans.

\section{Method}

\section{Participants}

The Chinese sample included 42 younger adults $(64.3 \%$ female, mean age $=21.00$, $S D=2.65$, range $=18-30$ years $)$ and 52 older adults $(69.2 \%$ female, mean age $=68.63, S D=5.81$, range $=60-82$ years) residing in Hong Kong, China. The American sample included 43 younger adults $(74.4 \%$ female, mean age $=20.40$, $S D=2.32$, range $=18-29$ years $)$ and 47 older adults $(68.1 \%$ female, mean age $=72.57, S D=6.54$, range $=62-86$ years) residing in Boston, USA. Younger adults from both cultures were recruited from local universities, and older adults were recruited from subject pools held by the universities as well as community centers in the same geographic areas as the universities by convenience sampling. 
Participants either received course credit or monetary payment for their participation. In the cross-cultural literature, American samples are considered to represent a more independent and individualistic thinking style, while Hong Kong Chinese-as well as other East Asians (e.g., Japanese) - are considered more interdependent and collectivistic (e.g., Hong et al. 2000).

\section{Measures and procedure}

After providing informed consent, participants reported demographic information, including age, sex, and education level (from " $1=$ less than 12 years" to " 10 = doctoral degree"). Perceived health was also measured by a single question that asked participants to make an evaluation of their current health state on a 5-point-Likert scale (from " $1=$ poor health" to "5 = excellent health"). After that, participants completed two measures of holistic thinking:

\section{Dialectical self scale}

The dialectical self scale (Spencer-Rodgers et al. 2001) was used to measure selfreported holistic thinking style. The scale was composed of 32 items, capturing the acceptance of contradictory statements and the likelihood to change according to context cognitively and behaviorally. Sample items include: "When I hear two sides of an argument, I often agree with both", "I often find that my beliefs and attitudes will change under different contexts" and "I often change the way I am, depending on who I am with". The inter-item reliability of the full scale, as indexed by Cronbach's $\alpha$, was .61 for the Hong Kong sample; after dropping five items, the reliability increased to .70. The corresponding Cronbach's $\alpha$ was .82 for the American sample. A composite score was created by taking the mean of the remaining 27 items. A higher score indicates a higher level of holistic thinking.

To ensure comparability across cultures, these 27 items were tested for factorial invariance among Hong Kong Chinese and Americans. Structural equation models (SEM) were calculated with EQS 6.1 for Windows (Bentler and Wu 1995), following the test procedure described by Byrne (2001, p. 173), as well as suggestions from Vandenberg and Lance (2000). We compared a baseline model in which all items were randomly parceled, without constraining anything with a constrained model, in which all paths from both cultures were fixed to be equal. The Chi square change was not significant, and the model fit indices of the constrained model were at an acceptable level, $C F I=.92, \quad G F I=.95, R M S E A=.07$, suggesting that the measures showed factorial equivalence across cultures.

\section{Framed line task (Kitayama et al. 2003)}

In this task, participants were shown a square frame with a vertical line in it. The participants were then shown a second square frame that was either larger than, smaller than, or the same size as the first frame. Participants were instructed to draw 
a line that was the same as the first one in terms of either the absolute length (the absolute task) or the proportion of the line relative to the height of the respective square (the relative task). Participants then went through 3 practice trials and 6 critical trials for each task. The order of the two tasks was counterbalanced across participants. Average error size (in millimeters) from the critical trials was analyzed. The absolute task requires participants to focus on the target line, whereas the relative task requires them to pay attention to both the target line and the surrounding square.

The framed line task was used to measure attention towards contextual information (Kitayama et al. 2003) to see whether the presence of a different context (i.e., a second square) could influence participants' judgment regarding the length of the line. Previous studies have demonstrated this measure to have good validity in detecting individual differences in holistic thinking (Nisbett 2007). For example, in the framed line task, the more attention one pays to contextual information, the better one will perform on the relative task and worse in absolute task, which makes the discrepancy between relative and absolute tasks an indicator of holistic thinking (Kitayama et al. 2009). Following the suggestion of Kitayama et al. (2009), we calculated the discrepancy between errors made in the absolute task and the relative task (i.e., error made in absolute task-error made in relative task) as an indicator of holistic thinking in the present study. A larger value indicates a higher level of holistic thinking.

In addition, several potential covariates were also measured, including measures on cognitive abilities: Forward and Backward Digit Span and the Digit Symbol Substitution Test (Weschsler 1981), the Mini-Mental State Examination (Folstein et al. 1975), and a verbal fluency task. The verbal fluency task asked participants to name as many animals as they could in $60 \mathrm{~s}$ (Spreen and Benton 1977). Finally, participants were debriefed by the experimenter.

Analysis plan

In the following analysis, we sought to test the age-related differences in two sets of tasks-the self-report scale and behavioral measure. The main emphasis was whether there were any culture differences in terms of age-related changes in holistic thinking. Hence, whenever a culture $\times$ age group interaction was found, we split the data by culture, to test the age-related changes, i.e., examining whether the age effect was significant in different cultures, instead of testing whether these cultural differences in holistic thinking differed by age.

\section{Results}

Preliminary analysis

A MANOVA with age group (younger vs. older adults) and culture (Chinese vs. American) as the between subject factors on education level, self-reported health, MMSE, digit span forward, digit span backward, digit symbol, and verbal fluency 
Table 1 Demographics and cognition

\begin{tabular}{|c|c|c|c|c|}
\hline & \multicolumn{2}{|l|}{ Chinese } & \multicolumn{2}{|l|}{ Americans } \\
\hline & $\begin{array}{l}\text { Younger adults } \\
(N=42)\end{array}$ & $\begin{array}{l}\text { Older adults } \\
(N=52)\end{array}$ & $\begin{array}{l}\text { Younger adults } \\
(N=43)\end{array}$ & $\begin{array}{l}\text { Older adults } \\
(N=47)\end{array}$ \\
\hline Age & $21.00(2.65)$ & $68.63(5.81)$ & $20.40(2.32)$ & $72.57(6.54)$ \\
\hline Sex & Female: $64 \%$ & Female: $69 \%$ & Female: $74 \%$ & Female: $68 \%$ \\
\hline Education level $^{\mathrm{a}}$ & $8.19(.40)$ & $1.62(1.24)$ & $6.00(1.60)$ & $8.64(1.13)$ \\
\hline Self-reported health ${ }^{\mathrm{b}}$ & $2.98(.92)$ & $2.56(.78)$ & $4.05(.72)$ & $3.89(.87)$ \\
\hline $\mathrm{MMSE}^{\mathrm{a}}$ & $29.45(1.02)$ & $28.27(1.46)$ & $29.77(.53)$ & $29.11(1.54)$ \\
\hline Digit span (forward) ${ }^{a}$ & $8.74(.59)$ & $7.67(1.13)$ & $7.72(1.08)$ & $7.62(.92)$ \\
\hline Digit span (backward) ${ }^{\mathrm{a}}$ & $6.62(1.51)$ & $3.69(1.13)$ & $5.42(1.37)$ & $5.62(1.42)$ \\
\hline Digit symbol $^{\mathrm{a}}$ & $28.48(3.90)$ & $11.27(3.67)$ & $25.44(4.21)$ & $19.47(3.44)$ \\
\hline Verbal fluency $^{\mathrm{b}}$ & $16.48(3.85)$ & $16.33(3.61)$ & $26.56(5.97)$ & $22.83(6.98)$ \\
\hline
\end{tabular}

Standard deviations are in parenthesis

MMSE mini-mental state examination

a Significant age difference at $p<.01$

b Significant age difference at $p<.05$

task revealed a significant age difference, Wilks' $\Lambda=.48, F(7,173)=20.82$, $p<.01, \eta^{2}=.51$, qualified by an age group $\times$ culture interaction, Wilks' $\Lambda=.16$, $F(7,173)=98.18, p<.01, \eta^{2}=.84$, suggesting that older adults in general had worse health, visual abilities, and cognitive abilities than did younger adults (see Table 1 for descriptive statistics). These variables were thus included as covariates in the following analyses.

Age differences in holistic thinking for different tasks across cultures

ANCOVAs with age group (younger vs. older adults) and culture (Chinese vs. American) as the between subject factors and controlling for the above-mentioned covariates were performed for the dialectical self scale and the framed line task.

\section{Dialectical self scale}

The Univariate ANCOVA on dialectical self scale revealed significant main effects of culture and age group, $F(1,179)=44.82, p<.01, \eta^{2}=.20$, and $F(1$, $179)=22.34, p<.01, \eta^{2}=.11$, respectively, while the culture $\times$ age group interaction was not significant, $F(1,179)<1$, n.s., suggesting that Chinese $(M=4.03, S E=.44)$ tended to endorse more dialectical thinking than did Americans $(M=3.53, S E=.64)$, and younger adults $(M=4.01, S E=.59)$ tended to show a higher level of dialectical thinking than did older adults $(M=3.59$, $S E=.54)$ (Please see Fig. 1). 


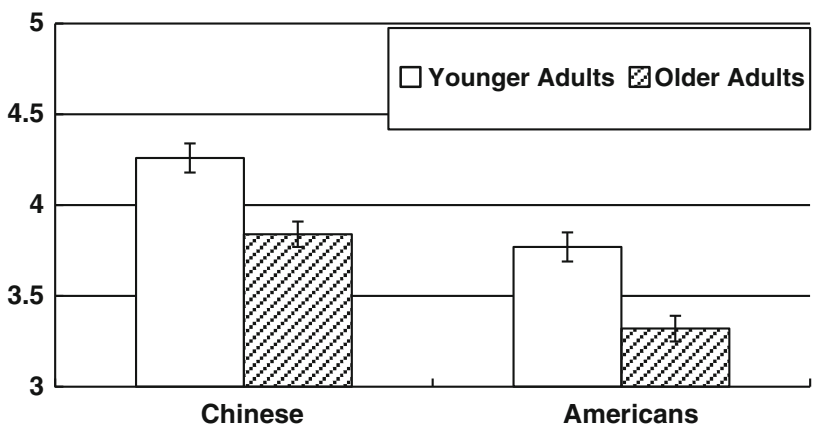

Fig. 1 Culture differences of self-reported holistic thinking across age. Note the error bars represent standard error of the mean

\section{Framed line task}

The Univariate ANCOVA on the discrepancy between errors made in the absolute task and the relative task revealed significant culture and age main effects, $F(1$, $178)=7.03, p<.01, \eta^{2}=.04$, and $F(1,178)=10.88, p<.01, \eta^{2}=.06$, respectively, qualified by a culture $\times$ age group interaction, $F(1,178)=12.34$, $p<.01, \eta^{2}=.07$. These results suggest that culture differences in the framed line task were different in the two age groups. To explore the culture $\times$ age group interaction, we ran a Univariate ANCOVA with age group as the between-subject factor in each of the two cultures. The age group main effect was only significant among Chinese, $F(1,92)=5.15, p=.03, \eta^{2}=.05$, indicating that older Chinese $(M=17.34, S E=1.79)$ showed a higher level of holistic thinking than did younger Chinese $(M=4.16, S E=1.87), F(1,90)=10.64, p<.01, \eta^{2}=.11$; yet, there was no age difference in the American sample (Younger adults: $M=6.46$, $S E=1.54$; Older adults: $M=7.23, S E=1.43), F(1,87)<1$, n.s. $(\text { see Fig. } 2)^{1}$

\section{Discussion}

In the present study, we examined age differences in holistic thinking across two cultures. In general, the well-documented culture differences in holistic thinking were replicated. Both measures - the dialectical self scale measuring self-reported holistic thinking, and the framed line task measuring the use of contextual

\footnotetext{
${ }^{1}$ A Culture (Chinese vs. American) $\times$ Age (younger vs. older adults) $\times$ Task (absolute task vs. relative task) mixed-model ANCOVA was conducted. A significant culture $\times$ age $\times$ task interaction was also found, $F(1,179)=8.42, p<.01, \eta^{2}=.05$, suggesting that younger and older adults in different cultures performed differently in the absolute task and relative task. A further split on task revealed that for the absolute task, there was a significant age $\times$ culture interaction, $F(1,179)=28.95, p<.01, \eta^{2}=.14$, whereas there were neither an age $\times$ culture interaction nor any main effect for the relative task. Moreover, it was found that older Chinese did much worse than the other groups. The pattern is similar to what we have reported using a discrepancy score as the dependent variable. For the purpose of simplicity, we only presented the age $\times$ culture interactions in terms of discrepancy.
} 


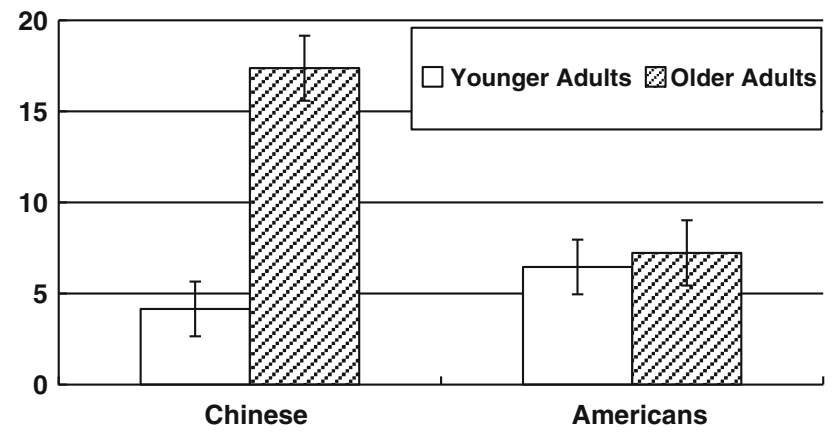

Fig. 2 Culture differences of performance on the framed line task (discrepancy between errors made in the absolute task and the relative task) across age. Note the error bars represent standard error of the mean

information, showed that Chinese were more likely to engage in holistic thinking than were Americans. However, and more importantly, the distinct age $\times$ culture interaction patterns emerged as expected, suggesting that self-report and behavioral measure of holistic thinking might have some underlying differences.

Specifically, in terms of self-reported holistic thinking, a negative association between age and holistic thinking was found in both cultures. This finding is in line with prior research in developmental psychology arguing that holistic thinking is not only a cultural construct but also a sign of cognitive maturity (e.g., Basseches 1984a; Blanchard-Fields and Norris 1994) that peaks in early and middle adulthood and decline in older age. Previous research has demonstrated that older adults perform worse in some basic cognitive tasks, including memory (e.g., Cohen 1996), attention (e.g., Salthouse 1994), and working memory (e.g., West 1996).If older adults find holistic thinking cognitively demanding, they may think less holistically compared with younger adults. However, prior studies on age differences in holistic thinking (Basseches 1984b; Kramer 1989) usually only included age groups up to middle-age where basic cognitive abilities were well preserved. Findings from these studies generally revealed that age was positively associated with holistic thinking. Our findings suggest that this positive association might not continue into old age. Adapting Diehl and Wahl's (2010) model of awareness of age-related changes, older adults' self-awareness of their cognitive declines might influence their thinking style. Accordingly, the possibility might be that that older adults' selfawareness of age-related decline in cognition could affect how they perform on an actual task. For example, Schofield and colleagues (Schofield et al. 1997) found that memory complaints predicted subsequent decline in cognitive tasks for older adults. In the self-reported dialectical thinking scale, older adults' awareness of their declining cognition might dampen them from thinking more dialectically, which could consequently result in a lower score on the measure.

In terms of the behavioral measure, Americans did not show any age differences in the framed line task. As predicted, Chinese older adults, compared with their younger counterparts, tended to make greater use of contextual information in 
solving the framed line task. Interpreting these findings using the model proposed by Park and colleagues, $(2010,1999)$ might reveal the two mechanisms-cognitive resources and socialization-that drive culture and age differences in holistic thinking. At the outset, cultural differences in holistic thinking might stem from sociocultural factors such as East Asians being more interdependent (Markus and Kitayama 1991) and living in more complex social networks with prescribed role relations (Nisbett 2003) than are North Americans. These cultural differences are reinforced by the respective child-rearing practices in the different cultures (Fernald and Morikawa 1993; Tardif et al. 1999). Growing old in one culture means being socialized in the culture for a longer period of time (Heine et al. 1999), and it also means being more motivated to pursue emotionally meaningful goals (Carstensen 2006) as defined by the culture (Fung et al. 2008). For tasks that do not require much cognitive resources, these cultural tendencies take over, and increase in intensity with age. These tasks are thus called the "culture-saturated" tasks by Park et al. (1999)In this study, the framed line task was such a task, and older Chinese were more likely to take the contextual information into account performing the task than were younger Chinese.

Conversely, for tasks that have a high cognitive demand, this demand is likely to increase with age, as a result of age-related declines in basic cognitive abilities, such as memory, attention and working memory (Hasher and Zacks 1988; Johnson 1990; Maylor et al. 2002). As the cognitive demand increases with age, there may come a point at which cultural tendencies can no longer support culture-specific cognitive processing, leading to reduced cultural differences on the task. For example, in a series of working memory tasks, Hedden et al. (2002) found that in simple task (i.e., digit span forward task), younger and older Chinese always outperformed their American counterparts, while in a difficult task (i.e., digit span backward task), younger Chinese still performed better than younger Americans, but there were not differences in terms of performance between older Chinese and Americans. And indeed, the distinct age $\times$ culture interactions in dialectical self scale and framed line task indicated that they might be measuring different underlying constructs as suggested by Park et al. (1999).

Surprisingly, we did not observe any culture differences in the framed line task among younger adults, which was in contrast to previous studies demonstrating that Japanese younger adults used more holistic thinking than did Americans (Kitayama et al. 2003, 2009). There might be two possible explanations for the nonsignificant results. First, this behavioral tendency for younger Hong Kong Chinese might be influenced by the colony history of Hong Kong, whereas the older population might still keep a traditional Chinese way of thinking. For example, Chow (2000) has claimed that Hong Kong "has been dominated by the Chinese... culture, though Western practices have also been prevalent, especially among the young and educated. Hong Kong is... a typical example of where the East meets the West (p. 158)". Second, the modern educational emphasis on analytic thinking in University might have also played a role in influencing the younger adults in both Hong Kong and America, making them more likely to think in a similar manner (i.e., focusing on both the target and background). Future studies might consider conducting the framed line task in a group of participants who have not gone through the modern 
education system (e.g., high school students without any formal University education).

We also acknowledge other limitations in the present study. First, while we directly examined culture and age differences in holistic thinking on two different measures, the exact mechanisms underlying these differences (or the lack of them) are just our speculation. Future studies should directly measure and test these mechanisms. Second, the education level of our older Chinese subsample was much lower than that of the other three groups. Although this is consistent with the demographic characteristics of the population in Hong Kong (Hong Kong Census and Statistic Department 2007), and we have statistically controlled for education in testing our hypotheses, this might be a problem in view of the previous literature that holistic thinking positively correlates with education (e.g., Kramer 1989). However, other researchers have argued that holistic thinking is a cultural-historical product, which might be education-irrelevant (e.g., Merriam 2004; Nisbett et al. 2001). Nevertheless, future studies should test the generalizability of our results by testing older Chinese with higher education levels. Finally, the absence of middleaged adults might make the generalizability of the present study limited; future investigations into this topic should consider adding a middle-aged sample for a comprehensive understanding.

Despite these limitations, the present study contributes to the literature by including older adults, as well as two different measures, in studying cross-cultural age differences in holistic thinking (i.e., the age $\times$ culture interaction). Findings showed that among measures that supposedly all measure the same constructholistic thinking (Nisbett 2007)_distinct patterns of age-related changes across cultures emerged, in ways that generally support the model proposed by Park et al. (1999). Future studies should note these differences in age-related holistic thinking across cultures and measures, and explore the mechanisms underlying these differences.

Acknowledgments The study was supported by the National Institute on Aging (Grant Numbers T32 AG-00204, and R01 AG-026323 to D. M. I.).

\section{References}

Basseches, M. (1984a). Dialectical thinking and adult development. Norwood, NJ: Ablex.

Basseches, M. (1984b). Dialectical thinking as a metasystematic form of cognitive organization. In M. L. Commons, F. A. Richards, \& C. Armon (Eds.), Beyond formal operations: Late adolescent and adult cognitive development (pp. 216-238). New York: Praeger.

Bentler, P., \& Wu, E. (1995). EQS for Windows user's guide. Encino, CA: Multivariate Software.

Blanchard-Fields, F., \& Norris, L. (1994). Causal attributions from adolescence through adulthood. Aging and Cognition, 1, 67-86.

Byrne, B. M. (2001). Structural equation modeling with AMOS: Basic concepts, applications, and programming. Mahwah, NJ: Lawrence Erlbaum Associates Inc.

Carstensen, L. L. (2006). The influence of a sense of time on human development. Science, 312, 1913-1915.

Chalfonte, B. L., \& Johnson, M. K. (1996). Feature memory and binding in young and older adults. Memory and Cognition, 24, 403-416.

Choi, I., Koo, M., \& Choi, J. A. (2007). Individual differences in analytic versus holistic thinking. Personality and Social Psychology Bulletin, 33, 691-705. 
Choi, I., \& Nisbett, R. E. (1998). Situational salience and cultural differences in the correspondence bias and in the actor-observer bias. Personality and Social Psychology Bulletin, 24, 949-960.

Choi, I., Nisbett, R. E., \& Smith, E. E. (1997). Culture, categorization and inductive reasoning. Cognition, $65,15-32$.

Chow, N. W. (2000). Ageing in Hong Kong. In D. R. Phillips (Ed.), Ageing in the Asia-Pacific region: Issues, policies and future trends (pp. 158-173). London and New York: Routledge.

Chua, H. F., Boland, J. E., \& Nisbett, R. E. (2005). Cultural variation in eye movements during scene perception. Proceedings of the National Academy of Science of the United States of America, 102, 12629-12633.

Cohen, G. (1996). Memory and learning in normal aging. In R. T. Woods (Ed.), Handbook of the clinical psychology of aging (pp. 43-58). Chichester: Wiley.

Diehl, M. K., \& Wahl, H.-W. (2010). Awareness of age-related change: Examination of a (mostly) unexplored concept. Journal of Gerontology: Social Sciences, 65B, 340-350.

Fernald, A., \& Morikawa, H. (1993). Common themes and culture variations in Japanese and American mothers' speech to infants. Child Development, 64, 637-656.

Folstein, M. F., Folstein, S. E., \& McHugh, P. R. (1975). "Mini-mental state": A practical method for grading the cognitive state of patients for the clinician. Journal of Psychiatric Research, 12, 189-198.

Fung, H. H., Isaacowitz, D. M., Lu, A., Wadliinger, H. A., Goren, D., \& Wilson, H. R. (2008). Agerelated positivity enhancement is not universal: Older Hong Kong Chinese look away from positive stimuli. Psychology and Aging, 23, 440-446.

Grossmann, I., Karasawa, M., Izumi, S., Na, J., Varnum, M. E., Kitayama, S., et al. (2012). Aging and wisdom: Culture matters. Psychological Science, 23, 1059-1066.

Hasher, L., \& Zacks, R. T. (1988). Working memory, comprehension, and aging: A review and a new view. In G. H. Bower (Ed.), The psychology of learning and motivation: Advances in research and theory (Vol. 22, pp. 193-225). San Diego, CA: Academic Press.

Hedden, T., Park, D., Nisbett, R. E., Ji, L. J., Jing, Q., \& Jiao, S. (2002). Cultural variation in verbal versus spatial neuropsychological function across the lifespan. Neuropsychology, 16, 65-73.

Heine, S. J., Lehman, D. R., Markus, H. R., \& Kitayama, S. (1999). Is there a universal need for positive self-regard? Psychological Review, 106, 766-794.

Hong Kong Census and Statistics Department. (2007). Hong Kong 2006 population by-census main report (Vol. 1). Retrieved 30 August 2010 from the Hong Kong Government Web site: http://www. censtatd.gov.hk/products_and_services/products/publications/statistical_report/population_and_ vital_events/index_cd_B1120047_dt_detail.jsp.

Hong, Y. Y., Morris, M. W., Chiu, C. Y., \& Benet-Martinez, V. (2000). Multicultural minds: A dynamic constructivist approach to culture and cognition. American Psychologist, 55, 709-720.

Ji, L. J., Peng, K. P., \& Nisbett, R. E. (2000). Culture, control, and perception of relationships in the environment. Journal of Personality and Social Psychology, 78, 943-955.

Johnson, M. M. S. (1990). Age differences in decision making: A process methodology for examining strategic information processing. Journal of Gerontology: Psychological Sciences, 45, 75-78.

Kitayama, S., Duffy, S., Kawamura, T., \& Larsen, J. T. (2003). Perceiving an object and its context in different cultures: A cultural look at new look. Psychological Science, 14, 201-206.

Kitayama, S., Park, H., Sevincer, T. A., Karasawa, M., \& Uskul, A. K. (2009). A cultural task analysis of implicit independence: Comparing North America, Western Europe, and East Asia. Journal of Personality and Social Psychology, 72, 236-255.

Kramer, D. A. (1989). Development of an awareness of contradiction across the life span and the question of postformal operations. In M. L. Commons, J. D. Sinnott, F. A. Richards, \& C. Armon (Eds.), Adult development: Comparisons and applications of developmental models (pp. 133-159). New York: Praeger.

Kramer, D. A., Kahlbaugh, P. E., \& Goldston, R. B. (1992). A measure of paradigm beliefs about the social world. Journal of Gerontology, 47, 180-189.

Kramer, D. A., \& Woodruff, D. S. (1986). Relativistic and dialectical thought in three age groups. Human Development, 29, 280-290.

Markus, H. R., \& Kitayama, S. (1991). Culture and the self: Implications for cognition, emotion and motivation. Psychological Review, 98, 224-253.

Masuda, T., \& Nisbett, R. E. (2001). Attending holistically versus analytically: Comparing the context sensitivity of Japanese and Americans. Journal of Personality and Social Psychology, 81, 922-934.

Masuda, T., \& Nisbett, R. E. (2006). Culture and change blindness. Cognitive Science, 30, 381-399. 
Maylor, E. A., Moulson, J. M., Muncer, A., \& Taylor, L. A. (2002). Does performance in theory of mind tasks decline in old age? British Journal of Psychology, 93, 465-485.

Merriam, S. B. (2004). The role of cognitive development in Mezirow's transformational learning theory. Adult Education Quarterly, 55, 60-68.

Morris, M. W., \& Peng, K. (1994). Culture and cause: American and Chinese attributions for social and physical events. Journal of Personality and Social Psychology, 67, 949-971.

Munro, D. J. (1985). Introduction. In D. Munro (Ed.), Individualism and holism: Studies in Confucian and Taoist values (pp. 1-34). Ann Arbor: Center for Chinese Studies, University of Michigan.

Na, J., Grossmann, I., Varnum, M. E., Kitayama, S., Gonzalez, R., \& Nisbett, R. E. (2010). Cultural differences are not always reducible to individual differences. Proceedings of the National Academy of Sciences, 107, 6192-6197.

Nisbett, R. E. (2003). The geography of thought: How Asians and Westerners think differently ... and why. New York: Free Press.

Nisbett, R. E. (2007). Eastern and Western ways of perceiving the world. In Y. Shoda, D. Cervone, \& G. Downey (Eds.), Persons in context: Building a science of the individual. New York: Guilford Press.

Nisbett, R. E., Peng, K. P., Choi, I., \& Norenzayan, A. (2001). Culture and systems of thought: Holistic versus analytic cognition. Psychological Review, 108, 291-310.

Norenzayan, A., Smith, E. E., Kim, B., \& Nisbett, R. E. (2002). Cultural preferences for formal versus intuitive reasoning. Cognitive Science, 26, 653-684.

Park, D. C., \& Huang, C. M. (2010). Culture wires the brain: A cognitive neuroscience perspective. Perspectives on Psychological Science, 5, 391-400.

Park, D. C., Nisbett, R. E., \& Hedden, T. (1999). Aging, culture, and cognition. Journal of Gerontology: Psychological Sciences, 54B, 75-84.

Peng, K. P., \& Nisbett, R. E. (1999). Culture, dialectics, and reasoning about contradiction. American Psychologist, 54, 741-754.

Salthouse, T. A. (1994). The nature of the influence of speed on adult age differences in cognition. Developmental Psychology, 30, 240-259.

Schofield, P. W., Marder, K., Dooneief, G., Jacobs, D. M., Sano, M., \& Stern, Y. (1997). Association of subjective memory complaints with subsequent cognitive decline in community-dwelling elderly individuals with baseline cognitive impairment. American Journal of Psychiatry, 154, 609-615.

Spencer-Rodgers, J., Boucher, H. C., Mori, S. C., Wang, L., \& Peng, K. (2009). The dialectical selfconcept: Contradiction, change, and holism in East Asian cultures. Personality and Social Psychology Bulletin, 35, 29-44.

Spencer-Rodgers, J., Srivastava, S., \& Peng, K. (2001). The dialectical self scale. Unpublished data.

Spreen, O., \& Benton, A. L. (1977). Neurosensory Center Comprehensive Examination for Aphasia. Victoria, BC: Neuropsychology Laboratory, University of Victoria.

Tardif, T., Gelman, S., \& Xu, F. (1999). Putting the 'noun bias' in context: A comparison of English and Mandarin. Child Development, 70, 620-635.

Vandenberg, R. J., \& Lance, C. E. (2000). A review and synthesis of the measurement invariance literature: Suggestions, practices, and recommendations for organizational research. Organizational Research Methods, 3, 4-70.

Weschsler, D. (1981). Manual for the Wechsler Adult Intelligence Scale-Revised. New York: Psychological Corporation.

West, R. L. (1996). An application of prefrontal cortex function theory to cognitive aging. Psychological Bulletin, 120, 272-292.

You, J., Fung, H. H. L., \& Isaacowitz, D. M. (2009). Age differences in dispositional optimism: A crosscultural study. European Journal of Aging, 6, 247-252. 